Familiar tourists, their behaviours and place attachments: an empirical framework

Jackie Clarke and David Bowen

Oxford School of Hospitality Management, Oxford Brookes Business School, Oxford Brookes University, Gipsy Lane, Headington, Oxford, OX3 OBP 


\title{
Familiar tourists, their behaviours and place attachments: an empirical framework
}

\begin{abstract}
Recognising the importance of familiar places in the lives of individuals and its prevalence in society, this paper examines the behaviours of familiar tourists and their relationships with their familiar places. Stimulated by conceptual work by Pearce (2012) alongside personal observation of the phenomenon, and with input from early focus group work, the fieldwork was conducted in two rural and peripheral destinations of Wales in the United Kingdom across peak and shoulder periods. This paper contributes a multi-level framework of familiar tourist behaviour rooted in the evidence. In unifying the study findings, the framework of familiar tourist behaviour emphasises the consumption behaviours of familiar tourists including the longevity and dynamic nature of the relationship between familiar tourist and their familiar place, the role of familiar tourist resources, skills and competencies, and the overarching theme of belonging.
\end{abstract}

\section{Keywords}

Familiar tourists; repeat tourists; familiar places; place attachment; tourist framework

\section{Introduction}

Within tourism academia, there is a predilection for the novel, exotic and far-off while much of the long-standing, commonplace and near-by slips past understudied. This empirical work seeks to recalibrate academic attention and fine-tune its appreciation of the less exciting, yet frequently practised form of repeat tourism captured by the concept of familiarity. Summarised and conceived as a touristplace relationship rich in connection and meaning, familiar tourists return to their familiar places time and again; places from childhood holidays, work, study or holidays in adult life. Most people can relate to familiar places from their own life experience and as a phenomenon addressed in everyday conversations. However it is often tinged with negativity by society and industry as the less glamorous tourism choice (for example, '9 out of 10 Brits suffer from Repetitive Holiday Syndrome', Staysure, 2015).

Tourism has been characterised throughout its history by the two features of dynamism versus inertia (Butler, 2015), the search for the new versus the comfort of the old. Familiarity in tourist behaviour, albeit in a different milieu, has theoretical lineage in Cohen's (1972) 'environmental bubble', an encasement of safety from which the tourist probes into the unknown territory of a new destination. For Cohen, 'the experience of tourism combines ... a degree of novelty with a degree of familiarity, the security of old habits with the excitement of change' (Cohen, 1972, p. 167). Early tourist typologies made use of the tension between novelty and familiarity (Cohen, 1972; Gray, 1970) and examined the role of novelty in destination decision making (Lee \& Crompton, 1992). Forty years on from Cohen's work, a conceptual paper by Pearce (2012) called attention to the neglected topic of individuals' experiences in visiting places of previous significance or familiarity and sought to shape research possibilities for such tourism to 'personally relevant locations' (Pearce, 2012, p.1027). A catalyst for our research, Pearce's paper lent substance to anecdotal observations of real-world tourist behaviour and reflections on our own relationships with familiar destinations. Working definitions evolved around the notion of 'personally relevant and oft visited locations for which the tourist has indepth knowledge and attachment', with a research focus on the consumption behaviours manifested in the relationship between familiar tourists and their familiar places. Recognition of familiar tourists as one particular sort of hybrid tourist (Boztug et al, 2015; Poon, 1993) came early in the research; a familiar tourist visiting their familiar place for one trip might be exploring a new destination on the next. One does not preclude the other, and familiar tourists can be sophisticated and experienced 
tourists. In the wider context, developing knowledge of familiar tourist behaviour and redressing the balance of academic endeavour has significance in a world attentive to climate change, to progressing individual and community well-being, and to building destination resilience.

The purpose of this paper is to examine and elucidate the behaviours of familiar tourists using empirical evidence across two destinations primarily focusing on consumption behaviour but with input from other literature. Cast by Pearce (2012, p. 2025) as a 'messy and multi-faceted' phenomenon, particular attention is given to advancing conceptual foundations relating to the fundamentals of familiar tourist behaviour. Innovative insights are explored regarding the resources, competencies and skills that familiar tourists bring to their consumption of familiar place. The paper makes an empirically-led contribution to the understanding and conceptual shaping of familiar tourists and the familiar places that they visit, recognising the phenomenon to stretch beyond the existing bodies of knowledge on repeat tourists, Visiting Friends and Relatives (VFR) tourists, and genealogy tourists whilst acknowledging the connections.

\section{Literature review of related scholarship}

This study of familiar tourists does not stem from a particular theory but from a complex real-life phenomenon. Its framing in the literature is expansive, in line with the nature of the phenomenon itself, with Douglas Pearce's (2012 p.10) observation on tourism research of a 'common need to span across different literatures', and to Pratt's (2008 p.497-8) proposition of an open theoretical frame not bounded by literature silos.

\section{Related forms of tourism}

Repeat tourists are allied to the concept of consumer loyalty. True loyalty might be summarised as the combination of positive relative attitude and repeat patronage, with strong repeat visitation accompanied by weak positive relative attitude equating to spurious loyalty (Dick and Basu, 1994 p.101). However, typical destination treatment of repeat tourists is led by frequency of visit rather than attitude; it is the patronage dimension that distinguishes (e.g. VisitBritain, 2017). Behavioural characteristics of repeat tourists as against first time tourists suggests comparative seasonal spread (VisitBritain, 2017), longer length of stay (Wang, 2004), and perceived reduction of risk and uncertainty during trip decision making (Lehto, O’Leary \& Morrison, 2009).

'Conservative vacationers' (Lehto, O'Leary \& Morrison, 2009 p.803) or the 'habitual vacationers' of Decrop \& Snelders (2005 p.126) are repeat vacationers, perceived as 'victims' of their passive personalities, who visit the same place almost each year. Characterised as risk adverse, routine users of decision rules with scant information search, such tourists are not high involvement decision makers. Habit becomes a simplifying strategy for decision making (Decrop \& Snelders, 2005). Habitual vacationers bear some resemblance to the popular public image of familiar tourists as boring and lacking in resources and imagination - the Repetitive Holiday Syndrome.

Whether segmented into VF and VR (Backer, Leisch, \& Dolnicar, 2017), VFR has received longstanding (e.g. Jackson, 1990) academic attention. Constituent sub-topics include VFR typologies and core distinctions between VFR as sole motivation versus hybrid forms (Moscardo, Pearce, Morrison, Green \& O'Leary, 2000), VFR use of commercial accommodation and destination spend (Backer, 2010; Griffen \& Nunkoo, 2016), and the role of VFR in crisis amelioration (Backer \& Ritchie, 2017). Shani \& Uriely (2012) examine host loss of privacy and psychological stress when sharing their place with their VFR, focusing on guest-orientated and host-orientated styles of hosting and the predominance of either home-related activities or visits to commercial attractions. Pearce (2012) foregrounds the connections between familiar tourists and VFR whilst emphasising that visiting home and familiar places (VHFP) is conceptually independent of VFR studies. In addition, genealogical tourists, alternatively labelled as ancestral, legacy, roots or family heritage tourists (Ray \& McCain, 2009) seek a generational sense of self and of their own world perspective (Santos \& Yan, 2010). 
Bridging the literatures on related forms of tourism and place attachment, the concept of nostalgia is conceived as a past-oriented emotion that is evident across different cultures (Wildschut, Bruder, Robertson, van Tilberg \& Sedikides (2014), and as a preference towards experiences associated with people, places or things common in one's youth (Holbrook \& Schindler, 2003). Nostalgic bonding with place might, for example, hinge on friendships and family, on rites of passage experiences, or on love of the homeland (Holbrook \& Schindler, 2003), suggesting linkage to VFR tourists, repeat or habitual vacationers, and genealogical tourists respectively. Nostalgia might also be experienced as vicarious nostalgia (Goulding, 2002) for periods before the birth of the tourist (for example, in the case of genealogical tourists) or as collective nostalgia (Wildschut et al, 2014) with an emphasis on sociality and group identities (for example, in the case of some VFR tourists). For some destination types, for instance, seaside resorts, research indicates a nostalgic connection between older tourists and the re-visited place (Jarratt \& Gammon, 2016).

\section{Space, place and place attachment}

Seminal geographical work by Tuan (1977) contended that space is essentially abstract until transformed into place and given meaning by social and cultural construction. Some forty years later, topophilia as love of place, the connections between people and place, and the wealth of meaning and experience tied to places remain prominent (e.g. Cresswell, 2014). As dynamic composites of tangible and intangible components, places are individually experienced and understood, experienced differently at diverse times and even experienced differently and conflictingly at the same time (Tilley, 2006). Thus, places are experienced as 'changing and competing narratives in and over time' (Warnaby \& Medway, 2013, p.345). Despite the centrality of place as a concept in tourism, Smith (2015) contends that it has to date received insufficient attention.

The concept of place attachment has importance for understanding the behaviours of familiar tourists in and towards their familiar place. As conceived by different disciplines, place attachment raises different nuances, for example, the symbolic meanings of settings for sociology, the bond between people and place for environmental psychology ( $\mathrm{Su}$, Cheng \& Huang, 2011), or its importance in creating destination loyalty for marketing (Ryan, 2010). Simplified to three core factors (Hammitt, Bucklund \& Bixler, 2006), place attachment intertwines firstly the characteristics of the physical environment, secondly human usage and interaction with the environment, and thirdly the psychological, social and cultural interpretations and constructed meanings of such people-place interactions. Place attachment has also been construed as two dimensions, that of place identity or an affective and symbolic attachment to place, and that of place dependence, referring to functional attachment to place (Gross \& Brown, 2006). Extending away from the dominance of natural and built environments typically associated with destinations, marketers have explored commercial place attachment arising from familiarity, authenticity and security provided by commercial experience settings (Debenedetti, Oppewal \& Arsel, 2014). Interestingly in industry-sponsored research, neuropsychologists demonstrated through functional magnetic resonance imaging that areas of emotional processing in the brain are activated by an individual's special place and that this response is greater than that to meaningful objects such as photographs or engagement rings (The National Trust, 2017). Thus the study concluded that significant places probably hold greater emotional importance for people than significant objects.

\section{Consumer operant resources and value co-creation.}

Destinations (or places) are firmly established as composites or amalgams of components woven together for the tourist experience (Murphy, 1985). More recent thinking drawn from consumer studies, in particular consumer skills and competencies and the operant resources of service-dominant logic (Lusch and Vargo, 2006; Vargo \& Lusch, 2004, 2008), offer the potential for deeper understanding of how familiar tourists create value from destination consumption by integrating their own resources with those presented by the destination. In this way of thinking, value is only proposed by destination or tourism providers, not exchanged as conventionally treated. Thus value-in-use is cocreated by the tourist consciously or unconsciously using selective resources, skills and competencies and interacting with destination resources to mould a unique meaning-laden consumption experience. 
Consumers (here principally tourists) act as 'resource integrators' (Baron \& Harris, 2008; Vargo \& Lusch, 2008, p.7) for value co-creation. Conceived at outset as open-source theory (Vargo \& Lusch, 2008), service-dominant logic was initially critiqued for insufficient recognition of 'consumers' rich value-creative competencies' (Arnould, Price \& Malsche, 2005, p.91), input now acknowledged as central to value co-creation (Vargo \& Lusch, 2016). Mobilising ideas from consumer culture theory, Arnould et al (2005) comprehended consumer operant resources as comprising social connections and networks (social resources), specialised knowledge and skills and amassed cultural schema (cultural resources) and individual sensorimotor and mental endowment (physical resources).

Service-dominant logic thinking and how it informs value co-creation has been absorbed into recent tourism research (e.g. Shaw, Bailey \& Williams, 2011). Suntikul \& Jachna (2016) sought to reconcile co-creation with place attachment, finding strong correlations between experience value and place identity. Prebensen, Vitterso \& Dahl (2013, p.256) demonstrated the importance of tourist operant resources as 'value-enhancing variables' within tourist experiences. These 'personal resources such as time, effort, money and knowledge' also feature in later work (Mathis, Kim, Uysal, Sirgy \& Prebensen, 2016, p.63) emphasising co-creation of experience and modifications to service offers. The characteristic of inseparability for tourism production and consumption is somewhat problematic in differentiating value co-creation (value-in-use) from co-production; in fact, use of the two terms across academia has resulted in 'much misunderstanding' (Vargo \& Lusch, 2016, p.8). In our research, we lean towards value co-creation in its original conception with an emphasis on the operant resources of familiar tourists as categorised (social, cultural, physical) by Arnould et al (2005) as the most usefully insightful. To paraphrase Ryan (2010, p.40), the familiar tourist literally becomes a (co-) holidaymaker rather than a holiday-taker under the conceptualisation of service-dominant logic and value cocreation.

\section{Research design}

To understand how familiar tourists behave and make sense of their 'life world' of familiar places (Kvale \& Brinkmann, 2009, p.28) in the chosen field areas and beyond, the data collection for this interpretative research progressed over two phases; the preparatory phase and the main fieldwork phase. Each phase involved specific data collection methods. The preparatory phase used focus groups with familiar tourists away from the fieldwork areas and also field visits to the two study areas to meet tourism industry gatekeepers. The main fieldwork phase used in situ interviews with familiar tourists, a self-completion written instrument with other familiar tourists, and interviews with tourism providers. The main fieldwork phase was conducted in the two field areas of Gower and Mawddach over a seven month period. Table 1identifies the structure of the research design and presents further details of its implementation.

For the preparatory phase, two focus groups with people who self-identified as familiar tourists with familiar places were conducted. These informants, as with other study informants, were treated as knowledgeable agents (Gioia, Corley \& Rook, 2012 p.17) able to explain their intentions, thoughts and actions with revelatory potential for new ideas. All focus group informants completed pro-forma sheets about their nationality, birthplace and places lived. As current residents in the same city-region as the researchers, informants were not necessarily British nor born in the UK but included other nationalities. Thus the familiar places that the informants drew into the focus group discussion included specific areas of the UK and other parts of the world (e.g. Lisbon, Mallorca, Jerash). Drawn from our critical assessment of the different literatures, a structured schedule of themes (Stewart, Shamdasni \& Rook, 2007) and an embedded word association task were used to set the parameters for the focus groups. Informants outlined their familiar places, the length of time of such familiarity and the frequency of visits; what they thought, felt and did in their familiar place; the meaning of the familiar place and whether they thought about it when absent; any negative aspects of their relationship with familiar place and what they thought the familiar place gained from them. They also alluded to novel and far-off destinations juxtaposed to their familiar place trips, evidence of their hybrid characteristics (Boztug et al, 2015; Poon, 1993) in building portfolios of visits with different 
purposes and motivations. The breadth of focus group topic coverage did not preclude reflective insight. Indeed, contributions were perceived as ‘deep’ (Tobias, Focus Group).

Concurrent with the focus groups, the preparatory phase also incorporated field visits to the two study areas of Gower (South Wales) and Mawddach (mid-Wales) which established connections and topic resonance with gatekeepers, such as local area tourism associations and local bank managers with tourism industry expertise. Alongside the literature review, analysis and diagramming of the transcripts from the focus groups and gatekeepers informed the construction of the research instruments to be used in the field. The schedules for the familiar tourist interviews, provider interviews and the structure of the written instrument were pre-tested away from the field areas with alternative informants meeting all but the field location criteria.

For the main fieldwork phase, the research design of familiar tourist interviews, written instrument and tourism provider interviews was replicated in both study areas (see Table 1). Accordingly, the two field areas formed the naturalistic settings (Rubin \& Rubin, 2005) for the self-reported behaviours of familiar tourists in situ, the unfolding over time of their consumption behaviours 'in the wild' (Moore, Smallman, Wilson \& Simmons, 2012, p.636). A formal opening definition for informant selection would have overly constrained the exploratory nature of the research. Instead, informants self-selected themselves as familiar tourists visiting a familiar place. In our research, and using the terminology of Prentice (2004) who discussed self-rated familiarity, the informants who self-rated themselves as familiar were also very able to 'self-describe' their familiarity.

In total there were in situ field conversations with 108 familiar tourists using interviews over two shoulder seasons (April-May and September-October) and one high season (June, July, August). Focused yet adaptive (Kvale \& Brinkmann, 2009), these recorded interviews were discursive accounts of rich insight on the lived experiences of familiar tourists with their familiar place. The research protocol ensured data was collected from familiar tourists across weekdays and weekends and from both tourist-dense and tourist-sparse sub-locations in Gower and Mawddach. The use of varied sublocations (e.g. beaches, bridges, settlements) ensured familiar tourists were interviewed whilst undertaking a range of activities which averted bias towards any one type of tourist. This sub-location design followed comments during the preparatory field visits of market research surveys that overemphasised coastal resort tourists (tourist-dense sub-locations) and precluded other types of harder-toreach tourists that also visited the area. The challenges of these field interviews included the disruptions and resumptions of interviews (e.g. sudden downpours of rain), finding familiar tourists in sparse sub-locations and finding the hard-to-distinguish familiar tourist in dense sub-locations. On occasion there was also a tension for the researchers between securing interviews in tourist-sparse sublocations and yet remaining sensitive to the reasons why people visit such areas (to reflect, meditate, appreciate peace and quiet).

The researchers recruited a total of 31 tourism providers in Gower and Mawddach to administer the self-completion written instrument on their behalf. The written instrument concentrated on open questions and was completed by other (non-interviewed) familiar tourists visiting either Gower or Mawddach during the research period. The researchers either collected the completed written instruments from the tourism providers during subsequent field visits or received them by pre-paid post. In all, a total of 132 usable written instruments were returned. This alternative method of expression and data collection, produced by the familiar tourist in privacy, counter-balanced the verbal and interactional nature of the face-to-face interviews (Holstein \& Gubrium, 2016).

Pre-arranged conversations with a total of 36 tourism providers operating in Gower and Mawddach encompassed visitor attractions, events, activities, accommodation (e.g. serviced, self-catering, camping and caravanning), entertainment, retail including arts and crafts, and tourism associations. With their front-line contact with tourists, such informants were mostly practiced conversationalists and natural collectors and re-counters of information. As one provider stated, 'people do like to offload. It's amazing what people want to tell you. It's quite a privilege really' (Melanie, Mawddach provider). Many providers gave narrative accounts suffuse with detail, with some providers using booking diaries as tangible recall devices. For the most part, tourism providers were knowledgeable 
agents who provided cumulative expertise on the behaviour of familiar tourists and their relationship to their familiar place from a contrasting perspective.

Thematic analysis formed the analytic strategy: discovering, interpreting and reporting repeated patterns of meaning across the data set (Braun \& Clarke, 2006). Adopting an iterative process, descriptive codes were generated for features of the transcribed data with subsequent diagramming and development of interpretative themes, and finally interrogation for an overall conceptualisation. In defining and refining themes and sub-themes, the researchers used in vivo, emergent, and a priori concepts as best captured the essence of a specific theme (Spencer, Ritchie, Ormston, O'Connor \& Barnard, 2014). Illustrative quotations re-connect the analytic narrative with the voice of the familiar tourist informant, using 'proof quotes' and 'power quotes' when especially memorable, concise or insightful (Pratt, 2008, p.501). The illustrative quotations from the interviews adopt the convention of a pseudonym for the informant, followed by the place (Gower or Mawddach), with the word 'provider' attached as appropriate. Adaptations around this convention are made for the focus group and written instrument quotations.

\section{Findings and Discussion}

This section is structured into four themes: temporal dimensions; spatial dimensions; routines and rituals; and resources, skills and competencies. An evidence-based framework for understanding familiar tourist behaviour concludes the discussion. A common narrative thread between the themes and the framework is the enduring yet chameleon nature of the familiar tourist-familiar place relationship in the lives of individuals.

The familiar tourists' sense of attachment and possession and the repercussions for personal identity were clearly apparent. Allusions to familiar place as 'home' (e.g. 'this will always be home', Christine, Gower), as possession (e.g. 'my playground', Steve, Mawddach), and of 'belonging' (e.g. 'I belong here', Informant 60, Mawddach written instrument) formed typical meanings of familiar place for familiar tourists. The cultural context of the two study areas gave additional insight to the phenomenon through the Welsh language with the notion of cynefin (Mawddach) and hiraeth (Gower). As pinpointed by Dalene (Mawddach provider),

There's another word as well which is very often used to describe how sheep know their territories. It's called cynefin, which is belonging. There isn't a direct translation for it but it's that sense of belonging in a particular place. It's what stops a sheep going into a field that it shouldn't be in, how they know their patch when they are roaming.

For example, in the case of a German tourist as relayed by Sally (Mawddach provider), 'she just turned up on the doorstep. She'd been in Ireland and she'd sort of felt Barmouth calling her and she came back'.

Familiar places are places of emotion and of longitudinal appreciation of emotion. For one familiar tourist, 'when I first saw the view across the estuary at 12 years old, I felt deeply yet inexplicably moved. This has not changed' (Informant 15, Mawddach written instrument), whilst Julie (Gower) recalled her childhood past and continued feelings as 'it's the same, it's beautiful, mega. Really, really, and it's very special to me'. A third familiar tourist wrote of

happiness at times, and I have felt sadness over loved ones that I have shared times and events whilst here but have since passed away. I find it calming, restful, as though a breeze passes through the mind and washes away the stresses of life (Informant 24, Mawddach written instrument).

For some familiar tourists, 'old fashioned nostalgia' (Lorraine, Mawddach provider) is central, intensified by nostalgic bonding (with place) that occurred during young adulthood (Holbrook \& Schindler, 2003) and chiming with seaside resort nostalgia (Jarratt \& Gammon, 2016). 


\section{Temporal dimensions}

Familiar tourists tend toward a high frequency of visit to the familiar place, sometimes extending to hundreds of visits, but with variety in annual patterns from regular structures with visits at set times of year to more irregular patterns. Sally (Mawddach provider) referred affectionately to one familiar tourist as 'a creature of habit' whilst Steve (Mawddach) labelled his visit spontaneity as 'just a spur of the moment thing'.

At the meta-level of evolution through time, intriguing patterns occur. Familiar tourists, taking into account their age, have relationships with their familiar place extending from a few years to long lifetimes. Sid (Mawddach) described his lifetime devotion to his familiar place,

I'm 72 now and I came here when I was 12 and I worked on a farm in Tal-y-bont for 12 months, [stacked] hay and looked after the cows and the sheep and this, and that and the other. That is how I fell in love. [Researchers' italics]

Frequency of visit and times of year might change pattern through a familiar tourist's life course. For example, Geoff (Mawddach) referred to holidays with children set within a regular pattern and recalled that 'it was always the last week in May, first week in June that we came'. Eddie (Mawddach), who was retired with greater flexibility, summarised that 'since we both retired we've been able to come more often. We come about three or four times a year'. Such patterns broadly accord with life cycle theory and vacation undertakings (e.g. Lawson, 1991).

Familiar tourists divide into those experiencing a continuous relationship with their familiar place, such as Steve (Mawddach) who currently visits 20-30 times a year and claimed 'we've never had a year without visiting; we might have gone an odd couple of months without visiting in the winter but that is about all' and those experiencing an interrupted relationship with their familiar place. Many familiar tourists take timeout or gaps in visiting their familiar place. These breaks in the relationship are triggered by a shift in life stage, for example in the period of young adulthood between leaving the family home and the establishment of a partnership or family. As illustrated by Sonya (Mawddach),

I would say it [a gap] was when I was starting my career proper, so 22, 23 maybe 24ish; roundabout there in my case. All of my siblings have done it [a gap] at one point or other. It seems to happen at some point between very late teen years and mid-twenties and then you start coming back again. [Researchers' italics]

Akin to Plog's (2002) venturesomeness, young people use their resources instead to explore new destinations typically returning to their familiar place to introduce a new partner or significant others to a place of special meaning for them. Other changes in life stage (divorce, retirement, death of family members) or life events (relocation of home distorting accessibility to the familiar place, reallocation of financial resources, spells of ill health) are also commonly cited catalysts for an interrupted relationship between familiar tourist and familiar place. Recounted by Sally (Mawddach provider), a family who had visited since 1981 experienced 'one year when the father had a heart bypass and they didn't come'. For Susan's familiar place (Mawddach), the retirement of a relative (VFR) triggered the interruption:

I first came here when I was a baby because my grandfather was stationmaster at Barmouth station, so they lived in a little cottage near the bridge. I came here sort of every year until I was five when my grandfather retired and then we didn't come back until I was married and had two children.

Informant 24 (Mawddach written instrument) recalled that 'my parents and one of my brothers died and revisiting became sad, as memories of fun happy times without them were hard'. Such catalysts, positive or negative, disrupted the relationship between familiar tourist and familiar place, causing a break in visitation. Of course, any given continuous relationship between familiar tourist and familiar place might stem from a shorter duration to date, always with the potential for future interruption over the individual's life course. The longer the duration the greater the likelihood of a gap occurring. 


\section{Spatial dimensions}

The relationship between place of residency and familiar place location in terms of distance and physical accessibility is an important element. Familiar places are generally accessible (in terms of distance, but also time, effort, finance) to facilitate the frequency of visit. This physical proximity may be partially responsible for the enduring societal label of familiar places as dull or boring; they are perceived as too close to home. Changes in residency, work or study locations can disrupt the familiar tourist-familiar place relationship if journey demands become onerous.

Related to the journey, the act of crossing recognised and meaningful boundaries by the familiar tourist (e.g. roads, bridges, mountain passes) signal both imminent arrival at the familiar place and an associated positive shift in mood and emotions. This is analogous to research on edges by Lynch (1960). In Gower, a couple described their familiar place boundaries as experienced during the journey:

(Dominic) 'It's almost exciting, as we approach Swansea: we like the run in, we're familiar with it now. Partially, of course, because it's at your journey's end. You've got the M4 motorway out of the way and you're looking forward to getting to the cottage, or wherever we're staying ...'

(Alex) 'The Severn Bridge is always nice, coming down. I think that's when it switches on'

The ways in which familiar tourists move through and use their familiar place can also alter across the duration of the relationship. As familiar tourists mature, they change the nature of their activities and the micro-locations within their familiar place where they are pursued. Whilst some familiar tourists remain loyal to specific accommodation providers, referred to by Dalene (Mawddach provider) as 'serial offenders', other familiar tourists migrate to new providers and areas within the familiar place. However, they remain close enough to maintain the rituals of returning to much-loved haunts.

Familiar tourists evoke their familiar places when spatially separated by home or work. Sonya (Mawddach) stated that 'I use the view across the estuary from above Arthog as a mental escape; I've visualised it through many boring meetings'. Julie (Gower) often summoned thoughts of Gower, 'especially at night when you can't sleep, I think of something ... think of the beach'. Familiar tourists conjure up images and mentally move around micro-locations, as exemplified by Susan (Mawddach) who 'can wander round this, around town and up on the hills in my mind'. They also make use of tangible objects with familiar place associations. A memorable and extreme example was recounted by Lucy (Mawddach provider): a couple bought 'the furniture that was in the bedroom that they used to stay in and they bought the bed and all the bedding that was in that room so they could have it at home and remember it'. In addition, digital technology aided evocation of familiar place when familiar tourists were absent; for example, viewing live webcams via familiar place websites.

With echoes of Cohen's (1972) environmental bubble, familiar tourists exploit their existing knowledge of familiar place and search for new micro-locations amongst the well-known areas. They actively seek the unfamiliar in the familiar. This behaviour emanates from the desire for exploration, variety and further understanding of the familiar place, to 'explore little crevices' (Mike, Focus Group) and draws some comparison to Plog's $(1974,2002)$ characterisation of allocentric or venturesomeness behaviour. This seeking of the unfamiliar in the familiar may be planned or spontaneous. Craig (Mawddach) described his impulsive behaviour on crossing his familiar place boundary,

I came over Dinas this morning and I thought "I've never actually walked up there". So I just parked the van and went for a walk for about an hour and a half 'cos I've never done it.

In following up tales in an old book, an elderly couple planned and succeeded in finding the renovated cottage. As Jill (Mawddach) recalled, 'it suddenly takes your breath away, that is what that place is like, you just suddenly come onto it'. A keen walker, Ruth (Mawddach) epitomises the spatial distances connecting the unfamiliar to the familiar, 
there are so many undiscovered secrets all the time and we always all say the same thing, you know, "gosh, we didn't know this was here". And yet it might be within half a mile of places that you know really well.

Existing knowledge acts as a framework on which to pin fresh discoveries. Already familiar with the honeypot micro-locations typically visited by tourists relatively new to a destination, familiar tourists are probing for new finds 'off-the-beaten track' (Dalene, Mawddach provider). Elaine (Gower) articulated the point,

It's not like being a visitor in that you could maybe come for a week and you've maybe not seen what you want to see. You [a familiar tourist] know where to go, where to walk and what to do. But there is always somewhere new to go. [Researchers' italics]

Spatially, familiar tourists are likely to be more widely dispersed across a destination than other tourists. Thus familiar tourists mix the familiar with the unfamiliar 'and kind of get all of it' (Tobias, Focus Group).

\section{Routines and rituals}

Familiar tourists develop habits or routines, everyday easy patterns of activity that fit with their sense of relaxation. Unlike new arrivals at a destination, they do not need to learn the basic details and less effort is required. As Eddie (Mawddach) explained, 'you fall into a routine basically'. The establishment of more specific rituals, considered as formal systems of scripted episodic behaviour (Rook, 1984) or 'traditions' (Sonya, Mawddach), serve to re-engage and to strengthen the bonds of the familiar tourist with the familiar place.

Familiar place rituals combine activities (and attendant artefacts), significant others, and specific focal points or hotspots to create 'must see' or 'must do' priorities for visits. Rituals may be exhibited towards the start of a visit (reconnection, and akin to Jafari's 1987 phase of orientation), during a visit (immersion) or towards the end of a visit (extrication, and akin to Jafari's 1987 phase of valediction). Hotspots can be principally characterised as those with natural features (e.g. mountains), man-made features (e.g. bridges), and businesses (e.g. pubs). Some hotspots are meaningful to many familiar tourists (e.g. for Mawddach familiar tourists, walking and reflecting on Barmouth bridge; drinking at The Last Inn). Other hotspots are intensely personal, intimate and even hidden away. Informant 46 (Mawddach written instrument) wrote that his ritual involved 'a quick walk up to the Birmingham soldiers, memorial flag and Cell-fechan', an obscure micro-location for most visitors.

Some rituals form part of the process of reconnection with familiar place close to arrival. As observed by Dalene (Mawddach provider),

the first thing they will do on their first day is they will go back to Barmouth and they will have fish and chips at The Mermaid. They will walk along the beach and they will go to Davy Jones Locker and have a coffee. You know, there are certain things that they will do. Or they'll walk up the Panorama and stand at that viewpoint looking out over the bay. And then when that's done, they come back and they spend time in Dolgellau or they go and explore this area. It's almost as though "I've got to do that because that's part of my reminiscing", my annual pilgrimage almost, and then they feel free almost to go and do other things.

Other rituals take place once the familiar tourist has reconnected with the familiar place and has moved on to seek immersion. Heather (Gower) outlined the ritual for her group,

I mean we love to swim off Rhosili, but there is a 'must do' about going down past the rectory, and sometimes walking along to Llangennith, going to Bury Holm, going on to Mewslade, Fall Bay, walking out to the headland. So there is lots of 'must do' places to walk. 
Although a given component (hotspots, activities, types of significant others) may be common for many familiar tourists, variations render the ritual unique to the individuals involved. As an example, Nelly (Mawddach provider) described the ritual of one familiar tourist;

she has lost a lot of weight with weight watchers and she always has her photograph taken underneath the [Barmouth] railway bridge of her ever-decreasing size. They always do the same. [Researchers' italics]

Powerful and often cited rituals revolve round death and remembrance of deceased friends and relatives. Sonya (Mawddach) relayed that 'a tradition is to go and walk up Fegla Fawr and have a picnic where Granny's ashes are scattered'. Towards the end of the visit, other rituals are bound with extrication from the familiar place and act as 'a final sign-off for people' (Dalene, Mawddach provider). Jill and Sid (Mawddach) explained on the day of departure, 'we go into the post office and get a blueberry cake and we eat that and then we set off home'.

Key to ritual creation and repetition by familiar tourists in their familiar places is its role as the 'red marker of time' (Janet, Focus Group). Although place-based events (walking festivals, kite festivals, yacht races and so forth) played a part for certain familiar tourists, societally-shared calendar events (e.g New Year) and particularly personal events (e.g. birthdays, anniversaries, honeymoons) were also prominent. One ritual for a family of familiar tourists involved choosing engagement rings. As the jeweller concerned, Richard (Mawddach provider) commented that

one engagement ring was made [by me] for the parents. It's now the engagement ring being made for the children. I don't think I'll still be here when the engagement ring is being made for the grandchildren. [Researchers' italics]

Thus familiar places serve as sites for key life events (e.g. proposing on Barmouth bridge) with symbiotic strengthening of both familiar place and event in terms of meaning, identity and memory for the familiar tourist. Accordingly, familiar places act as the backdrop to observing change, to 'watching how the past disappears and the present comes' (Mary, Focus Group), the red markers of time for familiar tourists.

\section{Resources, skills and competencies}

Familiar tourists integrate resources, skills and competences to co-create their consumption of familiar place. The familiar tourist is an experienced or specialist tourist at the specific destination of their familiar place. This familiarity allows them to make the best allocation of their operand resources (e.g. time and money). For example, 'you don't waste time' or 'get ripped off' (Janet, Focus Group) because familiar tourists already know the essentials and the 'real price of things' (Celia, Focus Group). Taking into account the totality of their overall touristic undertakings, familiar tourists may be experienced or relatively inexperienced travellers for other types of destination but we are concerned here with the utilisation, development (and onward transference) of their resources, skills and competencies in co-creating value from familiar place. Familiar place must be co-created through the integration of some configuration of familiar tourist resources (operant and operand) with the resources (operant and operand) of the destination. As summarised by Mary (Focus Group), 'you may know a very different city from somebody else, but it might be the same place'.

Familiar tourists, whether consciously or unconsciously, make use of selected social, cultural and physical operant resources (Arnould et al, 2005) to create value for themselves with the familiar place. For social resources, existing and often close relationships are nurtured within the familiar place through use of ritual, life events and shared memories through time. Other relationships in the social network are strengthened with selective introductions of friends, colleagues and extended family to the familiar place. These introductions can be accompanied or unaccompanied by the familiar tourist. For accompanied trips, those invited experience the new destination under the guidance of the familiar tourist host. Ruth (Mawddach) referred to a pre- nuptial gathering in the familiar place of a groom-tobe with friends introduced to the area for the purpose of the event and stated 'there were a few cutting comments in the best man's speech about how they got dragged up Cadair Idris [mountain]'. For 
unaccompanied trips, as summarised by David (Mawddach) 'I've sort of sold it to people as it were and they have come independently'. However, social contacts might also be consciously excluded from the familiar place or from hotspots. Janet (Focus Group) confided that 'there is one in particular that I never tell anybody where it is'. A new visitor introduced to the area through their social network may in due course convert the visited place to familiar place status.

Social resources are expanded through new relationships fostered by the familiar place. New relationships are established with other visitors. For instance, Lucy (Mawddach provider) described a friendship group forged in the familiar place; 'they are currently holidaying in Scotland together on a walking holiday so they've created a real friendship from meeting here'. New relationships are also established with familiar place residents. These new relationships anchored through familiar place are facilitated by the multiple visits through time, a characteristic of familiar places not typically shared with other types of destination. The relationships extend from a 'nodding' acquaintanceship (Eddie, Mawddach) through to established friendship, encapsulated by Dalene (Mawddach provider) as 'they've now become incredibly good friends of ours, so much so that when they come by we don't charge them anymore, they're just friends'. Between the nodding acquaintanceship and established friendships, Sal (Gower) recounted her parents' social relations with local people,

We became part of the community at Llangennith, it was very nice. We, my father, opened fetes and we just got involved in whatever was going on. We bought vegetables from local people and we supported the shops and stuff like that.

However, as long recognised in the literature (Mathieson \& Wall, 1982; Wei, Qian \& Sun, 2018), the relationship between host and guest at a destination may not be as authentic as believed, a quandary commented on by familiar tourists and tourism providers alike. Despite this tension, social networks for familiar tourists can be strengthened and/or extended through use of their familiar place; most familiar tourists are 'great advocates' (Lily, Mawddach) for their familiar places.

Cultural resources encompass specialised knowledge and skills (Arnould et al, 2006) and familiar places offer a concentration of knowledge of place away from the current home environment. This knowledge allows consumption decisions to be flexible, to adapt to weather conditions without frustration; to 'just play it all by ear' (Susan, Mawddach). Specialised place knowledge has two advantages for familiar tourists, functioning as a safe haven and as a magnifying glass.

Firstly, familiar places form a safe haven. Melanie (Mawddach provider) referred to familiar places as 'boltholes' with connotations of protection and nurture. Celia (Focus Group) called her familiar place 'safe and comfortable' for onward experimentation and skill development, whilst for Mary (Focus Group), familiar places 'build up your confidence'. Carol (Focus Group) explained that

I take more risks ... when it gets dark and you know this is something I should never do, but in a familiar place I am often coming off a hiking trail in the dark and I would never do that in an unfamiliar place.

The safe haven with its characteristic combination of place knowledge, confidence-building and risktaking enables the continued development of skills and competencies in, for example, associated hobbies and interests (e.g. mountain bikers familiar with the trails upgraded competencies with a skills improvement course).

Secondly, familiar places act as a magnifying glass for the ability to see and appreciate finely-tuned detail in the familiar place environment. Such heightened sensory awareness born of familiarity ensures 'every year I take photographs out there, even though it is the same view, but it has so many moods, so they are always different, different lights, different clouds, tide in, tide out' (Gemma, Mawddach). For Ted and Sue (Mawddach), 'we know the walk. We know every pebble. It is just so beautiful and there is always something different'. In a variation of the magnifying glass effect, familiar tourists observed and appreciated details of their cultural context. Some familiar tourists who were not Welsh themselves strove to navigate the Welsh language in their familiar place; their success was also dependent upon the extent of their existing cultural schema and ability to learn. 
From a tourism provider's perspective, familiar tourists require 'less hand-holding' (Judith, Mawddach provider), freeing provider operand resources of time and finance to focus on other tourist types. However, familiar places can also gain from the specialist skills and knowledge of familiar tourists who, because of their emotional attachment, are willing to contribute for the benefit of place; the familiar tourist as benefactor. Familiar tourists may actively contribute to specific causes within their familiar place. For example, Sonya (Mawddach) actively lobbied for the preservation of a village threatened by the proposed abandonment of a protective seawall. Furthermore, some destination providers used familiar tourists as provider surrogates to scout for new information and judge quality of options on their behalf. This information, rooted in trust, was used by the provider to advise other visitors where to go, what to do and how to spend. To illustrate, Nelly (Mawddach provider), referring to a familiar tourist couple, stated

I ask their advice because they're quite discerning about where they go and eat. I mean we recommend places but they go and give me feedback which is quite useful because they go and eat out more than I do so if they think somewhere has gone downhill, that's information for me to use.

For Dalene (Mawddach provider), 'it's almost sort of shared learning' as familiar tourists are

willing to share places that they've been to that may be we don't know about. It's their little bit of, almost bragging, that they know something we don't, which is quite nice. I don't mean that in a negative way at all but it is pride. It is pride in "ah have you ever found? Have you ever been to?" which is quite nice. Because invariably we will then go and explore that particular place and then we pass it onto other people.

With the longevity of familiar tourist and familiar place relationships over decades or lifetimes, the variation in physical resources in the guise of sensorimotor and mental capacities is unsurprising. It is reflected in the shift in hobbies and interests, as experienced by Steve (Mawddach)

It started with climbing and we would go camping and we would do weekends climbing and so on and it overlapped a bit with the [old gold] mines. We used to do a bit of underground work in the mines and things like that and then it got more to walking really [Researchers' italics]

The detail observed by familiar tourists may also mirror physical resources. For example, attention to the detail and praise of 'plaques' on seaside promenade seating (Geoff, Mawddach) corresponds to the physical resources of an elderly familiar tourist in need of frequent seating opportunities.

It may be that those familiar tourists with a combination of limited cultural schema, physical resources and operand resources are the ones inclined towards the more habitual and single familiar place visitation patterns akin to society's negative portrayal of the familiar place phenomenon - the repetitive holiday syndrome highlighted in the paper's introduction and Decrop \& Snelders' (2005) habitual vacationer. Those with more abundant configurations of resources mix familiar places with other destinations new and afar. General travel competencies cultivated in the safe haven of the familiar place e.g. how to 'really use your own resources to find accommodation' (Mike, Focus Group) can subsequently transfer to alternative tourism destinations.

\section{An evidence-based framework of familiar tourist behaviour}

Complementing the narrative, this evidence-based framework seeks to schematically organise and communicate the 'theoretical scaffolding' (D. Pearce, 2012, p.12) of familiar tourist behaviour associated with familiar places from a primarily consumer behaviour perspective (see Figure 1). It serves to unify and pull together the findings from the research as detailed earlier in the paper.

Configured as a multi-level framework, it depicts the familiar tourist behaviours in respect of familiar place through time and space (the lower level of the figure), the connections between familiar place visits and the resources, skills and competencies of the familiar tourist (the middle level of the figure), 
and - at the most abstract level - the sense of belonging (away from home) that familiar tourist familiar place relationships engender (the upper level of the figure). The framework is the outcome of the inductive approach of the research and unifies the most significant themes, concepts, and features and the relationships between them in a simplified form to capture the essence of the reality of familiar tourist behaviour. In doing so, the framework absorbs recent thinking on consumer behaviour as integration between tourist resources and place resources to co-create unique value alongside longstanding concepts such as ritual and self-identity, whilst indicating the dynamic nature of the phenomenon.

The framework is partially bounded by the field context of the study, duly acknowledged by the 'cultural context' in the upper level of Figure 1 and the Welsh expressions of cynefin and hiraeth (replaceable for other cultural contexts as indicated by italics in Figure 1). Similar notions for cynefin and hiraeth may be found, for example, in the German word heimat, the Chinese notion of Xin Ling Gui Chu as being the place where your heart belongs, and the Maori turangawaewae. In choosing field areas sharing characteristics of Welsh-ness, rural and coastal landscapes and habitations, and protected area status, the framework is derived from the complementarity of these settings. Accompanying limitations in such decisions are arguably offset by the original focus group research that most noticeably encompassed urban areas, landscapes of different topographical nature (e.g. deserts, islands) and a mix of cultural, national, and regional contexts. Nonetheless, the applicability of the framework of familiar tourist behaviour could usefully be tried out through future focused research in different destination situations (e.g. capital cities and urban environments; island settings; destinations in different life stages including rejuvenation and decline; other countries including developing countries and so forth). Likewise, the framework could be addressed specifically to international inbound, domestic (and the 'staycation'), or specific segment studies for in-depth examination. Such onward research would not preclude the daytrip behaviours of local residents to nearby places of special meaning to them, extending the tourism-derived framework to other forms of mobility behaviour.

\section{Conclusion}

An under-rated and even faintly maligned phenomenon in society, familiar tourism is worthy of study for its all-round prevalence, gentle commitment to psychological well-being, and unsung support of destinations. Rooted in original data from two destinations of cultural and topographical similarity, the framework of familiar tourist behaviour establishes the associated behaviours and resources used to attain the sense of belonging and emotional resonance. Leading on from Pearce (2012), we believe this study to be the first empirical research dedicated to the better understanding of familiar tourists and their familiar places. As such, our evidence-based framework of familiar tourist behaviour offers an early contribution to the shaping and knowledge of this pervasive form of tourism beyond its associations with repeat tourism, VFR and their ilk.

There are important implications for destination organisations arising from thriving familiar tourist communities. The not uncommon proximity between familiar tourist place of residence and familiar place location - the very accessibility of place - favours more pro-environmental travel. The spatial dispersion and temporal spread of familiar tourists alleviate destination honeypots and seasonal pressure-points. Familiar tourist use of their social resources introduces new visitors to the area detached from any official marketing budget and with the indirect costs (time, effort) largely borne by the familiar tourist making the introduction. The multiplicity of familiar tourist visits coupled with new visitor stimulation has implications for improved destination resilience and crisis recovery were the familiar tourist market better appreciated and understood. Moreover, in line with Smith's (2015) observation of place as nuanced and complex, an understanding of how co-creation serves to integrate the resources of familiar tourist and destination to construct unique experiences as 'value-in-use' grants fresh perspectives (for example, in storytelling) for destination marketing. Finally, the longevity of familiar place in the lives of individuals proffers stability and a long-term vision opportunity seldom brought to realisation by tourism destination organisations. 
In addition to the utility of the framework of familiar tourist behaviour for other situations, additional insights for future research arose from the study. The use of mobile technology and social media in the development, reinforcement and evocation of familiar place by familiar tourists merits research attention. Further refinement of the roles and patterns of ritual at the different stages of reconnection, immersion and extrication as indicated in the study findings offers a rich topic for onward and focused research, perhaps in differing cultural contexts. Finally, further development of the catalysts or antecedents of disruptions or gaps in the familiar tourist - familiar place visitation patterns and the corresponding triggers for visit recommencement would provide useful knowledge to destination organisations tasked with the practicalities of destination resilience.

\section{Funding}

This work was supported by British Academy/Leverhulme Trust (grant number SG130271) 


\section{References}

Arnould, E.J., Price, L.L. \& Malshe, A. (2006). Toward a cultural resource-based theory of the customer. In R.F. Lusch \& S.L. Vargo (Eds), The service-dominant logic of marketing: dialog, debate, and directions (pp. 91-104). London: M.E. Sharpe.

Backer, E. (2010). Opportunities for commercial accommodation in VFR travel. International Journal of Tourism Research, 12(4), 334-354.

Backer, E., Leisch, F. \& Dolnicar, S. (2017). Visiting friends or relatives? Tourism Management, 60, 56-64.

Backer, E. \& Ritchie, B.W. (2017). VFR travel: a viable market for tourism crisis and disaster management? International Journal of Tourism Research 10 Feb 2017, DOI: 10.1002/jtr.2102

Baron, S. \& Harris, K. (2008). Consumers as resource integrators. Journal of Marketing Management, 24(1-2), 113-130.

Boztug, Y., Babakhani, N., Laesser, C. \& Dolnicar, S. (2015). The hybrid tourist. Annals of Tourism Research, 54, 190-250.

Braun, V. \& Clarke, V. (2006). Using thematic analysis in psychology. Qualitative Research in Psychology, 3(2), 77-101.

Butler, R. (2015) The evolution of tourism and tourism research. Tourism Recreation Research, 40(1), 16-27.

Cohen, E. (1972). Toward a sociology of international tourism. Social Research, 39(1), 164-182.

Cresswell, T. (2014). Place. A short introduction. Chichester: Wiley-Blackwell.

Debenedetti, A., Oppewal, H. \& Arsel, Z. (2014). Place attachment in commercial settings: a gift economy perspective. Journal of Consumer Research, 40, 904-923.

Decrop, A. \& Snelders, D. (2005). A grounded typology of vacation decision-making. Tourism Management, 26, 121-132.

Dick, A.S. \& Basu, K. (1994). Customer loyalty: toward an integrated conceptual framework. Journal of the Academy of Marketing Science, 22(2), 99-113.

Gioia, D.A., Corley, K.G. \& Hamilton, A.L. (2012). Seeking qualitative rigor in inductive research: notes on the Gioia methodology. Organizational Research Methods, 16(1), 15-31.

Goulding, C. (2002). An exploratory study of age related vicarious nostalgia and aesthetic consumption. Advances in Consumer Research, 29(1), 542-546.

Gray, J.P. (1970). International travel - international trade. Lexington Heath, Kentucky: Lexington Books.

Griffen,T. \& Nunkoo, R. (2016). Paid accommodation use of international VFR multi-destination travellers. Tourism Review, 71(2), 90-104.

Gross, M.J. \& Brown, G. (2006). Tourism experiences in a lifestyle destination setting: the roles of involvement and place attachment. Journal of Business Research, 59, 696-700.

Hammitt, W.E., Backlund, E.A. \& Bixler, R.D. (2006). Place bonding for recreation places: conceptual development and empirical development. Leisure Studies, 25, 17-41. 
Holbrook, M.B. \& Schindler, R.M. (2003). Nostalgic bonding: exploring the role of nostalgia in the consumption experience. Journal of Consumer Behaviour, 3(2), 107-127.

Holstein, J.A. \& Gubrium, J.F. (2016). Narrative practice and the active interview. In D. Silverman (Ed.), Qualitative research, $4^{\text {th }}$ edition (pp. 67-82). London: Sage.

Jackson, R. (1990). VFR tourism: is it underestimated? Journal of Tourism Studies, 1(2), 10-17.

Jafari, J. (1987). Tourism models: the sociocultural aspects. Tourism Management, 8(2), 151-159.

Jarratt, D. \& Gammon, S. (2016). 'We had the most wonderful times': seaside nostalgia at a British resort. Tourism Recreation Research, 42(2), 123-133.

Kvale, S. \& Brinkmann, S. (2009). Interviews. Learning the craft of qualitative research interviewing, $2^{\text {nd }}$ edition. Thousand Oaks: Sage.

Lawson, R.W. (1991). Patterns of tourist expenditure and types of vacation across the family life cycle. Journal of Travel Research, 29(4), 12-18.

Lee, T. \& Crompton, J. (1992). Measuring novelty seeking in tourism. Annals of Tourism Research, $19,732-737$.

Lehto, X.Y., O'Leary, J.T. \& Morrison, A. (2009). The effect of prior experience on vacation behaviour. Annals of Tourism Research, 31(4), 801-818.

Lusch, R.F \& Vargo, S.L. (2006). Service-dominant logic: reactions, reflections and refinements. Marketing Theory, 6(3), 281-288.

Lynch, K. (1960). The image of the city. Cambridge, Massachusetts: Harvard-MIT Joint Centre for Urban Studies, The MIT Press.

Mathis, E.F., Kim, H., Uysal, M., Sirgy, J.M. \& Prebensen, N.K. (2016). The effect of co-creation experience on outcome variable. Annals of Tourism Research, 57, 62-75.

Mathiseon, A. \& Wall, G. (1982). Tourism: economic, physical and social impacts. Harlow: Longman Group Ltd.

Moore, K., Smallman, C., Wilson, J. \& Simmons, D. (2012) Dynamic in-destination decision-making: an adjustment model. Tourism Management, 33, 635-645.

Moscardo, G., Pearce, P., Morrison, A., Green, D. \& O’Leary, J.T. (2000). Developing a typology for understanding visiting friends and relatives markets. Journal of Travel Research, 38, 251-259.

Murphy, P.E. (1985). Tourism. A community approach. London: Methuen.

Pearce, D.G. (2012). Frameworks for Tourism Research. Wallingford: CABI.

Pearce, P. (2012). The experience of visiting home and familiar places. Annals of Tourism Research, 39(2), 1024-1047.

Plog, S.C. (1974). Why destination areas rise and fall in popularity. Cornell Hotel and Restaurant Administration Quarterly, 14(4), 55-59.

Plog, S.C. (2002). The power of psychographics and the concept of venturesomeness. Journal of Travel Research, 40(3), 244-251.

Poon, A. (1993). Tourism, technology and competitive strategies. Wallingford: CABI. 
Pratt, M.G. (2008). Fitting oval pegs into round holes. Tensions in evaluating and publishing qualitative research in top-tier North American journals. Organizational Research Methods, 11(3), 481-509.

Prebensen, N.K., Vitterso, J. \& Dahl, T.I. (2013). Value co-creation significance of tourist resources. Annals of Tourism Research, 42, 240-261.

Prentice, R. (2004). Tourist familiarity and imagery. Annals of Tourism Research, 31(4), 923-945.

Ray, N.M. \& McCain, G. (2009). Guiding tourists to their ancestral home. International Journal of Culture and Hospitality Research, 3(4), 296-305.

Rook, D.W. (1984). Ritual behaviour and consumer symbolism. Advances in Consumer Research, 11(1), 279-284.

Rubin, H.J. \& Rubin, I.S. (2005). Qualitative interviewing. The art of hearing data, $2^{\text {nd }}$ edition. Thousand Oaks: Sage.

Ryan, C. (2010). Ways of conceptualising the tourist experience. A review of literature. Tourism Recreation Research, 35(1), 37-46.

Santos, C.A. \& Yan, G. (2010). Genealogical tourism: a phenomenological examination. Journal of Travel Research, 49(1), 56-67.

Shani, A. \& Uriely, N. (2012). VFR tourism: the host experience. Annals of Tourism Research, 39(1), 421-440.

Shaw, G., Bailey, A. \& Williams, A. (2011). Aspects of service-dominant logic and its implications for tourism management: examples from the hotel industry. Tourism Management, 32(2), 207214.

Smith, S. (2015). A sense of place: place, culture and tourism. Tourism Recreation Research, 40(2), 220-233.

Spencer, L., Ritchie, J., Ormston, R., O’Connor, W. \& Barnard, M. (2014). Analysis: principles and processes. In J. Ritchie, J. Lewis, C.M. Nicholls \& R. Ormston (Eds), Qualitative research practice. A guide for social science students and researchers, $2^{\text {nd }}$ edition (pp.269-293). London: Sage \& National Centre for Social Research.

Staysure (2015). 9 out of 10 Brits suffer from Repetitive Holiday Syndrome. http://www.staysure.co.uk/lifestyle/about-staysure/9-out-of-10-brits-suffer-from-repetitiveholiday-syndrome. Accessed $24^{\text {th }}$ August 2015.

Stewart, D.W., Shamdasani, P.N. \& Rook, D.W. (2007). Focus groups: theory and practice. Thousand Oaks: Sage.

Su, H-J., Cheng, K-F. \& Huang, H-H. (2011). Empirical study of destination loyalty and its antecedent: the perspective of place attachment. The Service Industries Journal, 31, 27212739 .

Suntikul, W. \& Jachna, T. (2016). The co-creation/place attachment nexus. Tourism Management, 52, 276-286.

The National Trust (2017). Places that make us. Research report. Swindon: The National Trust. https://www.nationaltrust.org.uk/documents/places-that-make-us-research-report.pdf

Tilley, C. (2006). Identity, place, landscape and heritage. Journal of Material Heritage, 11, 7-32. 
Tuan, Y-F. (1977). Space and place: the perspective of experience. Minneapolis: University of Minnesota Press.

Vargo, S.L \& Lusch, R.F. (2004). Evolving to a new dominant logic for marketing. Journal of Marketing, 68(1), 1-17.

Vargo, S.L. \& Lusch, R.F. (2008). Service-dominant logic: continuing the evolution. Journal of the Academy of Marketing Science, 36, 1-10.

VisitBritain (2017). First-time and repeat visits to Britain. Foresight, Issue 149. London: VisitBritain Strategy and Communication Division.

Wang, D. (2004). Tourist behaviour and repeat visitation to Hong Kong. Tourism Geographies, 6(1), 99-118.

Warnaby, G. \& Medway, D. (2013). What about the 'place' in place marketing? Marketing Theory, $13,345-363$.

Wei, L., Qian, J. \& Sun, J. (2018). Self-orientalism, joke-work and host-tourist relation. Annals of Tourism Research, 68, 89-99.

Wildschut, T., Bruder, M., Robertson, S., van Tilburg, W.A.P. \& Sedikides, C. (2014). Collective nostalgia: a group-level emotion that confers unique benefits on the group. Journal of Personality and Social Psychology, 107(5), 844-683. 
Figure 1. The evidence-based framework of familiar tourist behaviour

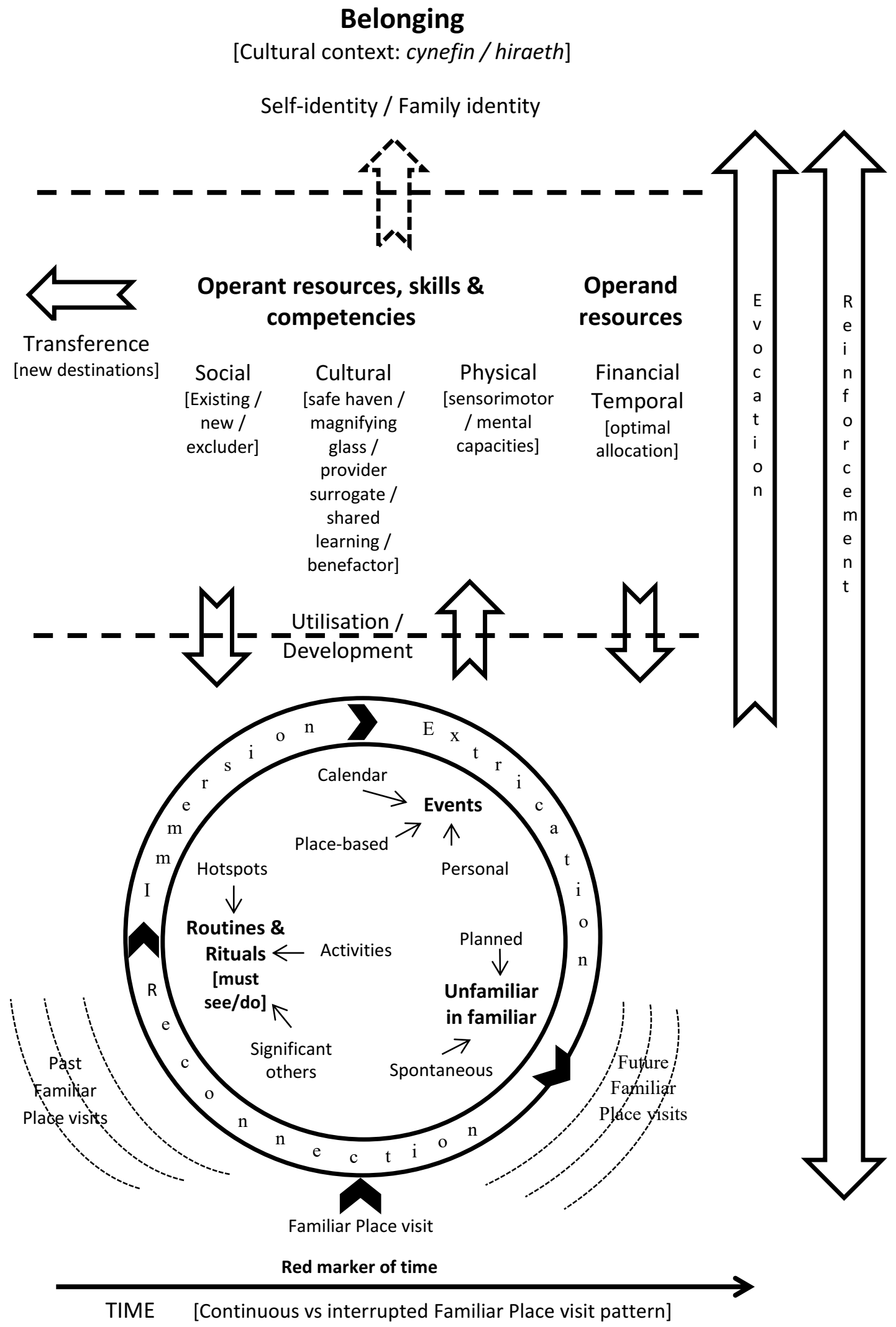


Table 1 Research design and implementation

\begin{tabular}{|c|c|c|c|}
\hline \multirow{7}{*}{ 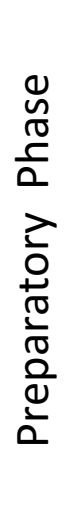 } & Focus Group One & Focus Group Two & Preparatory Field Visits \\
\hline & Location: Oxford, UK & Location: Oxford, UK & \multirow{3}{*}{$\begin{array}{l}\text { Gower: } \\
\text { Adventure activity organiser; Chairperson, local business } \\
\text { association; Chair of local branch, Institute of Welsh } \\
\text { Affairs; farmers with holiday caravan lets. }\end{array}$} \\
\hline & Duration: $1 \mathrm{hr} 20 \mathrm{mins}$ & Duration: $1 \mathrm{hr} 32 \mathrm{mins}$ & \\
\hline & No. of informants: 8 & No. of informants: 5 & \\
\hline & Informant profile: 4 male, 4 female; aged 31-75. & Informant profile: 1 male, 4 female; aged 26-65 & \multirow{3}{*}{$\begin{array}{l}\text { Mawddach: } \\
\text { Retired bank manager specialising in tourism industry; } \\
\text { local tourism association committee member; tourist } \\
\text { information centre staff }\end{array}$} \\
\hline & \multicolumn{2}{|c|}{ Informant nationalities: American, British, Irish, German, Jordanian, Portuguese. } & \\
\hline & \multicolumn{2}{|c|}{$\begin{array}{l}\text { Familiar places discussed: Lurgen; Paris; St Davids; Dublin; Lanzarote; Vienna; Braganca, Portugal; Anglesey; } \\
\text { India; Amsterdam; Lake District; Porthmadog; Peleponnese; London; Bourthmouth; Manchester; Plymouth; } \\
\text { Lisbon; Angola; Gera; Potsdam; Leipzig; Dresden; Toronto; Salt Lake City; Jerash; Spain; Mallorca; New York; } \\
\text { Los Angeles; San Francisco; Palm Beach. }\end{array}$} & \\
\hline \multirow{9}{*}{ 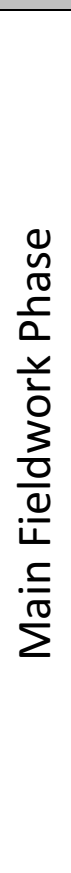 } & Familiar Tourist Interviews & Familiar Tourist Written Instrument & Tourism Provider Interviews \\
\hline & Gower: & Gower: & Gower: \\
\hline & $\begin{array}{l}\text { Field sub-locations: Six beach, cliff and settlement } \\
\text { micro-sites }\end{array}$ & $\begin{array}{l}\text { Field sub-locations: One of } 16 \text { possible tourism } \\
\text { provider's premises; privacy for written instrument } \\
\text { self-completion. }\end{array}$ & $\begin{array}{l}\text { Field sub-locations: informant's premises and public } \\
\text { spaces (cafes) }\end{array}$ \\
\hline & No. of informants: 67 & No. of informants: 69 & No. of informants: 13 \\
\hline & Informant profile: 33 male, 34 female; aged 18-71+ & $\begin{array}{l}\text { Informant profile: } 29 \text { male, } 40 \text { female; aged } 18-71+; \\
\text { duration of Gower familiar place relationship 1-10 } \\
\text { yrs } 19,11-20 \text { yrs } 9,21-30 \text { yrs } 7,31-40 \text { yrs } 7 ; 41-50 \text { yrs } \\
12,51+14 \text { (unrecorded } 1 \text { ) }\end{array}$ & $\begin{array}{l}\text { Informant profile: accommodation; outside pursuit } \\
\text { centre; campsite; surf shop; holiday village; restaurant; } \\
\text { and horse riding providers }\end{array}$ \\
\hline & Mawddach: & Mawddach: & Mawddach: \\
\hline & $\begin{array}{l}\text { Field sub-locations: Seven beach, spit point, coastal } \\
\text { settlement, inland estuary bridge, inland lakes, and } \\
\text { inland campsite micro-sites }\end{array}$ & $\begin{array}{l}\text { Field sub-locations: One of } 16 \text { possible tourism } \\
\text { provider's premises; privacy for written instrument } \\
\text { self-completion. }\end{array}$ & $\begin{array}{l}\text { Field sub-locations: informant's premises and public } \\
\text { spaces (cafes, village hall) }\end{array}$ \\
\hline & No. of informants: 41 & No. of informants: 63 & No. of informants: 23 \\
\hline & Informant profile: 24 male, 17 female; aged 18-71+ & $\begin{array}{l}\text { Informant profile: } 32 \text { male, } 31 \text { female; aged } 31-71+\text {; } \\
\text { duration of Mawddach familiar place relationship 1- } \\
10 \text { yrs } 18,11-20 \text { yrs } 14,21-30 \text { yrs } 6,31-40 \text { yrs } 11,41- \\
50 \text { yrs } 7,51+\text { yrs } 7\end{array}$ & $\begin{array}{l}\text { Informant profile: accommodation; visitor attraction; art } \\
\text { gallery; archivist (genealogy); mountain running race; } \\
\text { campsite; walking festival; theatre; mountain biking; arts } \\
\text { \& crafts; and caravan park providers. }\end{array}$ \\
\hline
\end{tabular}


Notes on contributors

Jackie Clarke is Reader in Marketing and Consumer Behaviour at the Oxford Brookes Business School, Oxford Brookes University. She is also a geographer by training and Fellow of the Royal Geographical Society with an early industry career in tour operation and aviation. Her research focuses on tourist behaviour and visitor experiences both at micro and destination level, with recent work examining the applicability of value co-creation in tourism and the arts, the visitor experience in the museum sector, and repeat visitation behaviours to meaningful destinations or familiar places.

David Bowen is Reader in Tourism Management at the Oxford Brookes Business School, Oxford Brookes University. Also a geographer, his main research interests revolve around tourist behaviour, especially tourist satisfaction, and tourism destination management. Current funded research projects include the familiar tourists-familiar places study and a project examining enclave resorts against non-enclave resorts in relation to economic dependency and sustainable tourism development. 